\title{
Teaching the teachers: ways of improving teaching and identifying areas for development
}

\author{
L Millard
}

What does "teaching the teachers" mean? The term refers to ways of enabling teachers to develop their ability to help students to learn. It can denote a range of activities and have a variety of outcomes. Boxes 1 and 2 outline some of these activities and outcomes.

When considering how teaching ability may be developed, it is helpful to bear in mind the breadth of opportunities available and also the varied outcomes which may be sought.

Well motivated teachers convey their enthusiasm to their students and this encourages them to learn. ${ }^{1}$ Teachers can be helped to maintain their motivation by knowing that they are doing a good job: that they are helping stu-

Box 1 Activities

- Attendance at courses on teaching

- Attendance at sessions on aspects of teaching, such as lecturing, running tutorials

- Having one's own teaching observed and commented upon

- Observing others teaching (learning by example)

- Discussion of issues, such as planning and evaluating a session, with a respected teacher

- Reflecting on one's own teaching and trying to identify what aspects are helpful to students' learning and which are not

- Studying student feedback, whether written or verbal, to identify what students report as being helpful and unhelpful to their learning

- Mentoring of a new teacher by an experienced colleague

1 Summerlands

Cottage, Botley Road,

Curdridge,

Southampton

SO32 2DS, UK

L Millard

lmillard@gpse.ac.uk

Accepted for publication 31 July 2000 dents to learn effectively. By enhancing teachers' understanding and abilities, teaching the teachers activities can help to nurture enthusiasm for teaching in the face of competing pressures from clinical and other demands.

How can teaching the teachers offer opportunities to hard pressed teachers to increase their ability to teach well and enjoy the process?

Medical schools, postgraduate centres, and numerous other providers offer courses on aspects of teaching and learning. Attending a course may well be the first thought of someone wishing to improve their teaching or of a colleague offering advice on how to enhance teaching skills. However, it is well worth considering a range of options and matching these to the person's requirements rather than just accepting what first comes to mind. The likelihood of making an appropriate choice is greatly increased by being clear about what one wants. If you want to have a beach holiday, you are unlikely to book a week in the Alps! Yet people often enrol for educational sessions and courses with rather hazy ideas about what they want or what will be offered to them. This is rather like picking a holiday more or less at random, rather then finding out exactly what is available and seeing if this meets your requirements. Spending time in thinking through some simple but important questions can help to ensure satisfaction with the eventual choice. Box 3 provides examples of questions which might be asked; others that are appropriate to specific teaching situations may occur to readers.

Having thought through their responses to such questions, teachers should be clearer about what they require in order to develop their teaching. This, in turn, will help with the choice of activity to meet these requirements. For example, if more feedback is desired, then this may be gained in a variety of ways, such as from colleagues observing teaching sessions and offering feedback on prespecified areas; from students through specifically designed feedback sheets or by discussion in focus groups; from videoed teaching and subsequent analysis, with or without the help of a colleague or educationalist.

If more information on the learning process is desired, then a textbook on learning in higher education or on the psychology of learning, 
Box 3 Questions teachers might ask themselves

- What is it that I want to be able to do differently?

- Do I need more knowledge about the learning process?

- Do I need to know more about the techniques and methods of teaching?

- Do I need to examine the way in which I view my teaching and, maybe, change this?

- Are my problems in teaching mainly organisational? For example, too few patients on the ward who are suitable for my students to learn from, or lack of a reasonable room in which to run an interactive small group session.

- Do I need to gain feedback about how I am doing as a teacher?

- Do I need more practice in certain areas, such as writing learning objectives or producing a lecture at a suitable level for first year undergraduates?

perhaps using the recommendation of a friend or colleague in the education department, is a good starting place. The point is that there are a number of ways of enhancing teaching ability besides enrolling on courses. To make good use of a course, or any other way of building knowledge or skills and enjoyment of teaching, it is important to have a clear view about what one wishes to learn and why. This does not imply that unexpected learning is not valuable; indeed it may prove of more worth than the intended outcome. However, time is precious and making a thought-through choice of a learning activity will increase the likelihood that the desired goal is achieved. Additional learning is then a bonus.

\section{What do courses have to offer teachers of medicine?}

Having suggested that attending a course is only one of a number of possible ways of teaching the teachers, it may be useful to outline some of the strengths of this method of teacher development as it is a commonly chosen option.

Whatever the aims and content of a course, this way of learning usually offers an opportunity for teachers to meet together to share experiences, ideas, problems, and strategies. This in itself can be immensely supportive and lead to creative problem solving and effective learning. A supportive and challenging group offers an environment that facilitates change and growth, which is why course organisers spend time on building group cohesion and encouraging honest feedback within a climate of respect and good humour. "Good" groups are more often the result of skilled organisation and facilitation than serendipity! Although some course participants may feel impatient about group-building activities, the canny will gain double value by both benefiting from the end product of these and analysing what seems to be effective and seeing how this might be translated into their own teaching situations.

Courses also often provide opportunities for practical work on issues related to teaching and learning. For example, subgroups might spend time devising a course evaluation sheet that could be copied and taken away to be customised by teachers to fit their own course or medical school requirements. Courses, such as "Training the trainers" run by the Royal College of Surgeons, or those run by a number of medical schools and other organisationsfor example, the Medical Education Interview Teaching Association, offer opportunities for participants to run short practice teaching sessions-"microteaching"-with subsequent feedback from other course participants. A commonly used format is for each course participant in turn to offer an episode of microteaching, followed by feedback from the other participants who have been taught during the microteaching. These small teaching sessions may involve interactive, didactic or, where practical skills are involved, hands-on teaching. Examples might be running a short discussion, teaching how to recognise osteoarthritic disease in the joints of the fingers, or training someone to tie a surgical knot. Microteaching may or may not be videoed, according to the objectives and the time available.

The format for giving feedback to the teacher, who is, of course, the prime learner in this situation, varies from course to course. Some use what are referred to as "Pendleton's rules"2 where the prime learner speaks first, and then other participants relate what they felt went well and what went less well and recommendations for improvement are made. Allowing the person who conducted the microteaching to say how s/he felt about the session before anyone else comments is important. It helps to give a feeling of control and removes the irritation of others commenting on points of which the person was only too well aware. However, Pendleton's format was developed in order to give feedback as part of the process of evaluating consultation skills. Sticking to a "what went well", "what went less well" structure for microteaching feedback from a number of learners can be less helpful, in the author's experience. The reasons for this are, firstly, that it polarises the comments into "good" and "bad", whereas feedback needs to reveal to the prime learner what the learner actually experienced, which may be neither negative or positive, or may contain elements of both. Secondly, people tend to pay less attention to the positive points as they wait to hear the bad news which they expect to follow. Box 4 outlines an alternative format for giving feedback, which works well for microteaching.

This format enables straightforward, honest feedback to be given within a safe structure, in which the emphasis is on learning from what actually happened rather than on hypothetical situations or remembered experience. The feedback is about what the learners actually did, felt, and thought and they report on this and on what they learnt. This is by no means always what the "teacher", the prime learner, 
had planned. It is interesting that things which the learners report as beneficial are sometimes seen as weaknesses by the prime learner. For example, deviating from the planned format to accommodate learning needs is valued by learners but downgraded by teachers if they see their prime task as covering content. The prime learner has control of how much, if any, advice is solicited. S/he also, of course, decides what to make of and how to use the feedback. S/he is encouraged to note and reflect on the comments which have been made, neither to take them on board wholesale or to reject those which may be unpalatable. Part of the role of the prime learner is to use the feedback to evaluate her or his own performance and to make decisions about what seems to encourage effective learning and what seems to hinder it. The more specific the feedback the more able $\mathrm{s} /$ he will be to see what may need to be changed and how to effect changes.

Space has been given to this description of microteaching and way of structuring feedback as, in the author's experience, many teachers find it a powerful and useful method of learning. If readers are considering attending a

\section{Box 4 An alternative format for giving} feedback

- The microteaching session takes place with a course participant acting as teacher and therefore the prime learner

- An observer who may be the course organiser or may be a course participant takes notes in chronological order

- After the microteaching, the prime learner and those who have been taught, make brief notes about the experience

- The course organiser invites the prime learner to say how s/he found the experience and whether s/he thinks that the learning outcomes were achieved and to make any other pressing comments

- The course organiser then invites each participant in turn to say what they learnt and how they felt about the experience. Participants are asked to use "I" statements and comment only on what they actually experienced, to be specific, and to avoid interpretation ("I think you meant...") or advice giving ("I think you should ...")

- When all participants have spoken, the observer adds points not already covered, again sticking to what was actually observed and striving to be clear and specific

- If appropriate, the course organiser may add comments if there are points which have been missed and to emphasise positive points

- Finally, the prime learner has a chance to make any further comments, but is encouraged not to justify or defend. Advice can be invited if required at this stage. The prime learner is invited to note down one or two key learning points at the end of the session course as a way of enhancing their teaching ability, the use of microteaching is something to look out for. It may sound heavy going. In fact, it is fun as well as useful. "A highlight of the course", is how microteaching is often described.

Having looked at activities that will enable teaching ability to be developed, the next section considers a way in which teachers can identify which areas of their teaching might benefit from these activities. Stages in the process of teaching are examined.

\section{PIE as a means of identifying areas of teaching which may benefit from development}

Teaching may be viewed as an activity that has 3 key phases:

Phase I: Planning

Phase II: Implementation

Phase III: Evaluation

This makes an easily remembered acronym-PIE. Teachers seeking to improve their abilities can ask themselves, "Which bit do I want to focus on?" The three phases may be subdivided to highlight areas of importance.

PHASE I: PLANNING

Box 5 lists questions appropriate to phase I, planning.

Box 5 Phase I: Planning-questions

1 Students

- What year/level?

- What have they experienced and covered so far?

- What knowledge and skills should they have?

- What will they be going to do later in the course?

2 Learning outcomes

- What exactly do I want students to be able to do by the end of this teaching episode?

3 Content

- What information do the students need to gain and/or what skills do they need to practice and/or what experiences do they need to have in order to attain the outcomes I have listed?

- How will I structure the content?

4 Timing

- How much time has been allocated?

- How much time should I give to each section?

5 Methods etc

- What methods/techniques/teaching aids will be appropriate to achieve the outcomes?

6 Assessment

- Will there be any?

- Will it be formative or summative?

- Will the students receive feedback and if so, how?

7 Practical points

- Venue, equipment - are they suitable to meet the outcomes? 
Outcomes (see phase I, 2) and other parts of the plan may have to be modified in the light of what is practicable, which means that the planning phase tends to be iterative as areas are re-examined to accommodate changes. Once questions such as those above have been answered, then a detailed programme will need to be written. Problems in responding to questions in this phase give pointers about where development is needed. For example, if the teacher is unclear about what methods will help fulfil the planned outcomes, then activities which build understanding of how to choose teaching methods and increase the repertoire of these are likely to be helpful.

The planning phase is crucial to the success of a teaching session, yet it is a part which is often skimped. As a teaching the teachers activity for a group, asking for written responses to the prompt questions above is often productive. For instance, the exercise will frequently result in teachers identifying for themselves the need for more precise information about the students and the curriculum. Gaining this can help to avoid unnecessary repetition of material which results in bored, and maybe inattentive, students. It also helps to prevent unplanned gaps in students' learningfor example, where assumptions are made by individual teachers about what the syllabus covers at certain points.

Writing learning outcomes during the planning phase is an area where teachers are likely to need help. Here a short, practical session of a couple of hours working with peers, can be invaluable. This might take the form of definitions and explanation followed by giving the group a set of statements to label as aims or as learning outcomes (that is, behavioural objectives). ${ }^{3}$ This can be a lighthearted exercise followed by the more serious activity of teachers writing learning outcomes for their own sessions.

PHASE II: IMPLEMENTATION

Phase II, implementation, covers the actual teaching session and may therefore involve any or all of the types of teaching referred to in box 6.

These three areas are often referred to as skills, knowledge, and attitudes. The literature on the psychology of learning refers to Bloom's ${ }^{4}$ three domains: psychomotor, cognitive, and affective. This more precise language may be helpful despite its less user friendly sound. Certainly, there are problems associated with giving a single label of "skills" to an area

\section{Box 6 Phase II: Implementation}

1 Building skills - for example, the ability to examine a shoulder joint

2 Transmitting information-for example, describing the key features of the locomotor system

3 Encouraging students to examine their attitudes - for example, by running a small group discussion on impaired mobility such as communication, which has elements of more than one domain. Precise language may also help teachers to think more clearly about other complex areas, such as physical examination, which require knowledge and suitable attitudes in addition to physical skill if they are to be performed in a professional and competent manner. Labelling such areas simply as "skills" may mask the richness and variety of the tasks involved and thus hamper adequate planning and implementation of teaching. It may cause teachers to overfocus on certain aspects while underemphasising others, such as attitudes or the role of knowledge in the performance of many tasks in medicine.

Implementation may require the use of teaching aids, such as a Power Point presentation, a computer quiz for students to work on individually, or the basic, yet serviceable, tools of blackboard and flip chart.

Areas within the implementation phase which cause difficulties for the teacher or the students indicate the need for teaching development of some kind. Again, what is required may be anything from simply practice in using teaching aids to reading and reflection on learning and teaching, leading to changes in planning and then alterations to the actual teaching session.

New teachers may need help in understanding the relation between what they plan (phase I) and what actually happens (phase II). An introductory course on teaching or an experienced colleague will point out that keeping to the stated start and finish times is essential, while other aspects of the planned session should be modified to meet students' needs which, almost inevitably, will vary in some respects from expectations. There is little point in running a teaching session, however well planned, if it does not meet the learners' needs. It is important that teachers make active choices about changing their plans and that these changes are firmly based on judgments about the students' needs. This will help to ensure that deviations from what was planned improve the session, rather than allow it to drift and lose focus.

Part of the implementation phase may involve assessment of students. This may range from a written examination to informal comments on performance or could include students' assessments of each other or self assessment, perhaps with the aid of a log book or learning portfolio. Whether assessment is built in or not, students will benefit from feedback on their learning; without this, improving performance is difficult. Feedback on achievements increases students' motivation as well as helping them to build on what has been learnt. ${ }^{5}$ Despite this, feedback tends to be hurried or squeezed out of teaching sessions. It is well worth trying to ensure that this element does not get lost during the implementation phase. Many teachers benefit from help in how to give feedback (see section on microteaching above). Both feedback and assessment are potential areas for teaching development. 
PHASE III: EVALUATION

This phase requires teachers to undertake structured critical examination of their ability to promote learning. It involves gathering information on what was learnt, making judgments about the effectiveness of the teaching in bringing about that learning and about the usefulness of the learning which has been achieved. As before, questions can help initiate thinking about the topic. Box 7 provides examples of questions to prompt thinking.

Some ways of obtaining the information to help answer these questions has been given earlier (page 760, column 2). Making judgments about the effectiveness and value of what has been taught constitutes the most important part of evaluation. The collection of data merely enables this to happen. Discussion with colleagues, either other teachers or full time educationalists, can stimulate critical evaluation and provide support. A well written textbook ${ }^{6}$ may be helpful too. It is worth finding

\section{Box 7 Phase III: Evaluation}

1 Were the planned outcomes achieved?

2 In retrospect, were these appropriate?

3 What seemed to help the students to learn?

4 What seemed to hinder their learning?

5 What can I do about these factors?

6 How satisfying was the teaching for me and why was that?

7 What does that tell me for next time?

8 Do I need any help with teaching and, if so, where will I get it? the time to write down a small number of key points to remember when planning future teaching, even if no formal, written evaluation of a course or session is required. Quality assessment processes are increasingly requiring teachers not only to improve their teaching but also to give evidence that they have done so. (All UK medical schools are currently being assessed by the Quality Assurance Agency under the Quality Assessment of Education scheme.) Recording and then using the results of evaluation constitutes an important quality enhancement loop; quality management and enhancement is one of six areas assessed by the Quality Assessment of Education scheme.

\section{Final words!}

Teaching is a complex task. Good teaching is vital if we are to have good doctors and medical scientists in the future. There are numerous ways of developing and supporting teachers. The author hopes that some of the ideas discussed in this paper will help teachers to find their work fulfilling and, more often than not, fun.

1 Brown G, Atkins M. Effective teaching in higher education London: Methuen, 1998

2 Pendleton D, Schofield T, Tate P, Havelock P. The consultation: an approach to learning and teaching. Oxford: Oxford University Press, 1984:68-72.

3 For a brief introduction to this subject see UCoSDA Briefing Paper Twenty-Eight, December 1995. (The Universities' and Colleges Staff Development Agency, University of Sheffield, Sheffield S10 2GJ, UK.)

4 Child D. Psychology and the teacher.London: Cassel, 1993:384, 390.

5 Rowntree D. Assessing students: How shall we know them? London: Harper and Row, 1997:24-7.

6 Rowntree D. Educational technology in curriculum developRowntree D. Educational technology in curriculum
ment. 2nd ed. London: Harper and Row, 1982. 